\title{
Electronic Reading and Writing in Spoken and Written Arabic: A Case Study
}

\author{
Raphiq Ibrahim (Corresponding Author) \\ Edmond J. Safra Brain Research Center For the Study of Learning Disabilities, University of Haifa, Israel; \\ Learning Disabilities Department, University of Haifa, Israel \\ Haitham Y. Taha \\ The Learning and Cognitive Laboratory, Special Education Department, Sakhnin College, Israel; \\ Edmond J. Safra Brain Research Center For the Study of Learning Disabilities, University of Haifa, Israel \\ Ayat Abu Dabous \\ Learning Disabilities Department, University of Haifa, Israel \\ Asaid Khateb \\ Edmond J. Safra Brain Research Center For the Study of Learning Disabilities, University of Haifa, Israel; \\ Learning Disabilities Department, University of Haifa, Israel
}

\begin{abstract}
Reading and writing disabilities and generalized cognitive dysfunction are developmental in origin and are likely linked to abnormalities in brain function. In this article, we detail selective reading and writing disturbances in the spoken and written Arabic orthography of an Arab teenager (RL) who communicates with his friends via readable and understandable electronic messages. We examine the performance of RL, who was diagnosed as learning disabled, in his reading and writing of Arabic words and text in Latin orthography compared to his reading and writing in Arabic orthography. Cognitive and verbal abilities in Arabic and Latin electronic orthography were tested using traditional pen and paper as well as electronic devices. The results underline the importance of the effect of the type of Arabic orthography on reading and writing fluency.
\end{abstract}

Index Terms — learning disability, reading, diglossia, Arabic, orthography, Latin, electronic

\section{INTRODUCTION}

Learning disability is a term that describes a variety of disabilities that affect the acquisition, remembering, understanding, organization or use of verbal and non-verbal information. The most common learning disability (70\%-80\%) is in reading (dyslexia). Formally, dyslexia is defined as a specific learning disability that is neurological in origin and characterized by difficulties with accurate and/or fluent word recognition and by poor spelling and decoding abilities. For instance, children with dyslexia may, through hard work and special education, learn to compensate for their difficulties, so that by adulthood they no longer appear to have a serious problem with reading (Shaywitz et al., 2003).

The term "Developmental Dyslexia" is often used as a synonym for reading disability. However, many researchers assert that there are different types of reading disabilities, of which dyslexia is one. A reading disability can affect any part of the reading process, including difficulty with accurate and/or fluent word recognition, word decoding, reading rate, prosody (oral reading with expression) and reading comprehension. Children with developmental dyslexia suffer from severe reading problems despite normal intelligence and normal instruction conditions and the absence of sensory problems (Snowling, 2000). Snowling (2000) describes "Developmental Dyslexia" as constellations of deficits which include: difficulties in learning to read, spelling problems and general slowness in symbolic information processing. However, other problems experienced by dyslexics also indicate difficulties with perceptual processes (visual and auditory), motor co-ordination, attention and memory (Stein, 2001). Children with dyslexia score poorly on tests of oral language expression and comprehension (Bishop, \& Snowling, 2004). These difficulties typically result from a deficit in the phonological component of the language that is often unexpected in relation to other cognitive abilities and the provision of effective classroom instruction (Lyon, Shaywitz, \& Shaywitz, 2003). Recent research has indicated that dyslexia can be considered as a deficit in the process of phonological information processing (Vellutino, Fletcher, Snowling, \& Scanlon, 2004). That includes deficits in phonological awareness and phonological processing (Gallagher, Frith, \& Snowling, 2000). Zabell and Everatt (2002) claimed that children with developmental dyslexia show difficulties from the beginning of reading and writing acquisition. A variety of different types of acquired dyslexia have also been identified. As these subtypes are caused by localized brain injury, their effects on the reading process can be quite specific. Similarly, the symptoms manifested by an acquired dyslexic will depend on which aspect of the reading process has been selectively compromised (Bishop, \& Snowling, 2004). 


\section{PhOnOlOGicAl And SuRface Dyslexia}

According to the "Dual Route Model" of Coltheart, Rastle, Perry, Langdon, Ziegler (2001), successful reading relies on two routes: the sub-lexical route and the lexical route. Only when both of these procedures are functioning adequately is an individual able to read all forms of text. In the sub-lexical route the letters are decoded by grapheme-phoneme rules of the alphabetical orthography. This procedure involves the division of written words into graphemes (letters or groups of letters), the mapping of sounds or phonemes to those graphemes, and the blending of the sounds together to produce a pronunciation. A problem in the sub-lexical route causes phonological dyslexia. People with phonological dyslexia show difficulties in decoding new words since reading new words that are not in their lexicon requires grapheme-phoneme decoding process (Zabell \& Everatt, 2002).

The second route is the Lexical Route that relates to written words as complete patterns. The orthographic or visual representation of the word in the mental lexicon allows pronunciation of the word. This route represents the mechanism by which the sight vocabulary is accessed and words are recognized as patterns without the necessity of phoneme-grapheme decoding. A problem in this route causes surface dyslexia. People with surface dyslexia have difficulties in accessing the "visual vocabulary" and they rely on the sub-lexical route to recall the pronunciation of a word. As a result, they show difficulties reading irregular words (Zabell \& Everatt, 2002). (See, Figure 1 for the Dual Route Model).

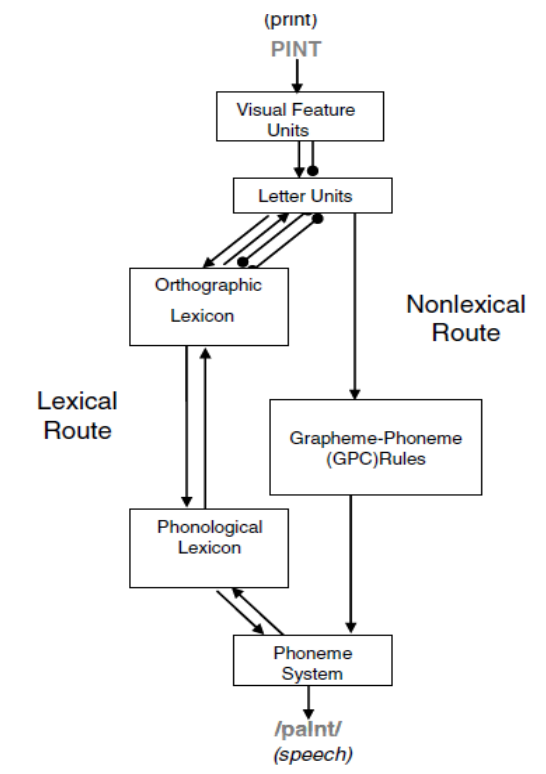

Figure 1. The Dual Route Model, Coltheart et al. (2001)

Other researchers define phonological dyslexia as specific severe deficit in phonological processing, while surface dyslexia is characterized by a general delay in word recognition (Stanovich, Siegel \& Gottardo, 1997).

In regard to 'writing disorder', impaired written language ability may include impairments in handwriting, spelling, organization of ideas, and composition. The term "dysgraphia" is often used as an all-encompassing term for all disorders of written expression. Some others, such as the International Dyslexia Association, use the term "dysgraphia" to refer exclusively to difficulties with handwriting.

\section{READING DisABILITIES AMONG ARABIC SPEAKERS}

Low levels of literacy have consistently been reported in Arabic-speaking countries, among both young readers (PIRLS, 2006) and older adolescent readers (PISA, 2009). Similar findings have emerged when comparing literacy achievements within Israeli society between Hebrew and Arabic speakers. Among Arabic speakers in Israel, some evidence indicates that reading rates are lower when reading their native Arabic (L1) as compared to reading non-native (L2) Hebrew (Ibrahim, Eviatar \& Aharon-Peretz, 2007). Many researchers (e.g., Myhill, 2009) have suggested that some of these difficulties are attributable to the so-called "diglossia" phenomenon in Arabic (see below), first described by Ferguson (1959) to refer to the existence of a high-prestige literary language and a low-prestige spoken dialect(s). The difference between these two varieties of Arabic is manifested in a substantial divergence in semantic, phonological, and even syntactic structures. There is wide agreement that this diglossic situation is a serious obstacle to literacy for young learners (see, for example, Iraqi, Feitelson, \& Share, 1992; Myhill, 2009; Saiegh-Haddad, 2005), but there is also evidence that other factors, principally the graphemic-orthographic features of written Arabic, may also partly account for the difficulties of learning written Arabic (e.g., Abu-Rabia, Mansour \& Share, 2003; Abu Ahmad, Ibrahim \& Share, in press; Elbeheri, \& Everatt, 2007). For example, a study by Ibrahim, Eviatar and Aharon Peretz (2002) examined the effects of orthography on letter and numeral processing. In that context, adolescent Arabic speakers for whom Hebrew 
is a second language were asked to perform a Trail Making Test in oral and visual versions. The findings revealed no difference between the oral versions, but, in the visual version performance was quite slower in Arabic. The authors hypothesized that the complexity of Arabic orthography slows letter and word identification. A later study by Ibrahim et al. (2007) found that the visual complexity of Arabic orthography causes unique difficulties among native Arabic speakers/ readers even compared to their own ability to read L2 Hebrew. A number of developmental studies (e.g., Abu-Ahmad et al., in press) have also demonstrated that acquiring decoding skills in Arabic is a particularly challenging task for the beginning reader.

Elbeheri, \& Everatt (2007) found in their study about literacy ability and phonological processing among normal and poor readers that there are relationships between literacy ability, decoding and phonological processing. In addition, they found that Arabic dyslexics show signs of poor phonological skills. The study supports the view that dyslexic Arabic children have impairments in the phonological processing domain.

\section{Diglossia}

Modern Standard Arabic (MSA) or literary Arabic is the form of Arabic used for reading and writing acquisition. The difference between the spoken dialect of the Arabic speaker and the written language that he/she acquires through formal instruction in school represents a classic case of Diglossia (Ayari, 1996). In such a diglossic context, MSA appears to some extent as a foreign language for native speakers of colloquial Arabic dialects. Hence, some authors consider literate monolingual Arabic speakers as bilingual speakers. This fact might explain the low rates in Arabic literacy among native speakers of Arabic, since it might be just as difficult for some native speakers of Arabic to acquire literacy in written Arabic as it is difficult for anyone to acquire literacy in a foreign language.

In the last decade, with the advent of electronic writing in media such as SMS, email messages and Messenger, young Arabic speakers have begun to develop their own writing systems. These improvised writing systems were based on writing the colloquial language in Arabic letters or in Latin alphabets. They use this improvised writing system as a way to deal with the complexity of Arabic and with the diglossia phenomenon of Arabic. This phenomenon is explainable by the argument that children learn to read most efficiently when the language of their primary schooling is as close as possible to their native dialect, and it is obvious that standard Arabic is quite different from the spoken dialects. Thus, it is reasonable to assume that it would be more efficient for poor readers to acquire literacy using the spoken dialects.

\section{ARABIC ORThOGRAPHY}

Standard Arabic consists of an alphabetical system that includes 28 basic letters. It is written and read from right to left. All of the letters are consonants but three letters also serve as long vowels (Abu-Rabia, 2007). In Standard Arabic there is a correspondence between letters and their sound in texts that are written with short vowels (which are represented by diacritics above or below the letters). Arabic Orthography written with short vowels is considered a shallow orthography and serves beginning readers, while Arabic orthography that is written without short vowels is considered as "deep orthography" and is intended for advanced readers (Abu-Rabia, Share \& Mansour, 2003). In addition, Arabic orthography has another characteristic. Most Arabic letters have more than one written form, depending on the letter's position and connectedness in a word: beginning, middle or end, in addition to more rules for different written shapes for each letter (see Taha, Ibrahim \& Khateb, 2013).

Letter recognition is critical for pronunciation and reading of words, and it requires considerable cognitive attention. This recognition is influenced by: the letter's shape, the diverse writing rules in different positions and the identification of the different short vowels under, in, and above the letters (Abu-Rabia et al., 2003). Furthermore, some of the letters have similar shapes and the only difference between them is the number and the position of dots: either on, in or under the letter. Dots appear within 15 letters; 10 letters appear with one dot, three have two dots and two have three dots. These dots are part of the consonant letters (Abu-Rabia, 2007). In addition, the diacritical marks which are the short vowels (/a/, /u/, /e/, /sukoon/, /shadda/) contribute to the phonology of the Arabic alphabet. The short vowels in Latin orthography are the letters in a word, whereas in the Semitic orthographies such as Arabic, the short vowels are not letters, but rather they appear on the letters and contribute to the correct pronunciation of words (Abu-Rabia, 1997). Furthermore, the vowelization of the word endings represents the grammatical function of the word in a sentence (Abu-Rabia, 2007). Also, of the unique characteristics of Arabic orthography is the fact that a number of letters (graphemes) share the same letter form (derived from Nabatean which had fewer consonants) and are distinguished only by the position and the number of consonant (dot) diacritics. For example, - ث - ت represent the consonants /t/, /b/ and /th/ respectively. Some adaptations of the Arabic "abjad" (e.g., Sindhi is southern India), include up to 7 or even 8 diacritical variants of the identical letter-form. An additional unique feature of Arabic orthography is that the majority of letters vary in shape according to position in the word; word-initial, medial or word-final position. It is worthy to

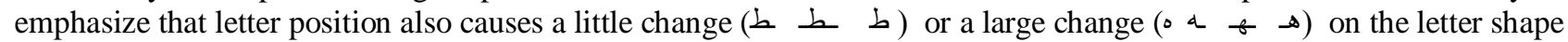
(for more examples see Appendix A). Six letters, however, have only two variant shapes which depend not only on the position in the word but also on the preceding letter $\mathrm{J} / \mathrm{r} /, \mathrm{j} / \mathrm{z} /, \mathrm{s} / \mathrm{d} /, \mathrm{j} / \mathrm{th} /, \mathrm{g} / \mathrm{w} /$ and $\mathrm{I} / \mathrm{a} /$. This subset of letters may connect only from the right side(لوح,, Lawh) but not from the left, (ولد, ود, , Walad). This sub-group of letters, therefore, 
may appear to the reader to be more separated or "distinct" in a word, that is, visually separated from adjacent letters. Thus, orthographically, Arabic presents unique challenges for the young reader despite the fact that grapheme-phoneme relations in the traditional (orthographic depth) sense are considered as highly regular or consistent.

A study by Taouk and Coltheart, (2004) investigated reading acquisition in Arabic among children and adults. In one experiment they attempted to examine the naming of real pronounceable 'position-illegal' words; which are written with a wrong letter variant according to its position. They found that children's word reading was significantly impaired when incorrect positional variants were substituted for the correct variants. This finding provides evidence that positional variants of letters affect word reading. Recent study that was conducted by Khateb et al. (Submitted), showed that the effect of variants of letters shapes and connectivity on word recognition in Arabic can be modulated by the reading age and proficiency.

\section{ELECTRONIC WRITING}

In the last 20 years people have been introduced to electronic writing. Younger people are generally introduced to electronic writing before they have fully developed the literacy skills based upon the established norms associated with the printed word. Therefore, it is natural for them to simply transfer their established writing conventions to electronic media when these became available. It is noted that in certain contexts in which there is a feeling that the language should be more colloquial (e.g. email messages, SMS messages, and often blogs), they feel relatively free to ignore normal writing conventions to achieve this end. Because Arabic, in which the spoken (colloquial) language differs significantly from the standard written Arabic (referred to as diglossia, see section IV), and in which the spoken form has no written form, this colloquial way of writing has become very common. Electronic media (as emails, SMS messages, and in most cases blogs) have become the usual avenue of written communication for young Arab people. This means that in this case where there is no established way to write the spoken language, young Arab people have no choice but to devise ad-hoc orthography, not necessarily even in the same alphabet as that which is used to write their standard language. In Arabic, more than in any other language, this phenomenon has begun to receive the attention of academic researchers (see e.g. Warschauer, El Said, and Zohry 2002, Wheeler 2003, Palfreyman and al-Khalil 2003). Garra (2007) has shown that various orthographic systems for representing the different varieties of spoken Arabic are beginning to take shape. There are cases in which local written standards are beginning to develop. For example, Arabic speakers from the northern region in Israel/Palestine today generally write electronically using a written version of the spoken dialect where there are actually 7 different phonemes which are commonly represented with numerals in the writing system: 2 for /ء/ hamza" and / ق "qaaf", 3 for / ع/ "ayin", 3' or 8 for / / / "ghain", 5 or 7' for / خ / "khaa"”, 6 for / $ث /$ "taa", 7 for $/ \tau /$ "haa'“ when all of these can also be represented without numbers. For example, the letter $\dot{\varepsilon}$ "ghayn" could be represented (in descending order of relative frequency) as $\langle\mathrm{g}\rangle,\langle 3$ ' $>,\langle\mathrm{gh}\rangle,\langle 8\rangle$, or $\langle$ g' $>$, with none of these versions particularly dominating.

\section{The INFLUENCE OF ARABIC ORTHOGRAPHY ON READING}

Abu Rabia, \& Taha, (2004), examined the reading and spelling errors of dyslexic Arabic readers compared to normal readers. The results of this study indicate that similar reading and spelling error profiles were observed among dyslexics and the reading-level-matched group. In addition, they found a clear influence of the Arabic orthography and its morphology on reading and spelling. For example, the irregular pronunciation rules and visual letter confusion. An important finding in the study of Ibrahim, Eviatar, \& Aharon Peretz (2002), was that reading a text in Arabic is harder for Arabic-speaking children than reading a text in Hebrew among Hebrew-speaking children. This difference was attributed to the complexity of Arabic orthography which increases the perceptual load and so slows word recognition in Arabic. This finding supports the hypothesis that visual processing is important in reading Arabic, and the difference in visual letter processing between Arabic and Hebrew is primarily influenced by visual or orthographic and not by phonological factors.

The findings of Ibrahim and his colleagues' study inspired the present study that aimed at examining the influence of orthography on reading and writing fluency of a teenager who was diagnosed as learning disabled. The purposes of the present study were: first, to examine the performance of a teenager who was diagnosed as learning disabled in reading and writing Arabic words in Latin orthography in a comparison to reading and writing in Arabic orthography; second, to examine the performance in writing of Arabic text using Latin orthography by handwriting versus writing electronically.

The hypotheses of this study were: first, the performance of the participant in writing and reading in the Latin orthography will be better than his performance in writing and reading in the Arabic orthography, second, the performance of the participant in writing electronically will be better than handwriting.

\section{Methodology}

Case Report: RL is a 13.3 year old teenager, who studies in the 8th grade in a private school in Nazareth. RL is right-handed. He speaks Arabic as his first language, and began to study Hebrew in third grade and English in the fourth grade.

$\mathrm{RL}$ is the third son in a family that includes 5 siblings and parents. His father is a contractor, his mother is a 
housewife. His youngest sister has been diagnosed as dysgraphic, and his oldest brother had learning difficulties during his school years.

According to the mother's report, the pregnancy and childbirth were normal. Developmentally, no problems were reported in motor and speech development.

Medically, RL was hospitalized once due to a congenital injury in his neck muscle that affected his head movement, he was able to move his head only to one side. As a result, he had a surgery when he was three years old.

RL was diagnosed with a learning disability. He was diagnosed twice by the educational psychologist of the school; once when he was eight years old and again when he was 11 years old.

RL was directed to diagnosis by his parents due to low academic achievements and educational difficulties. His difficulties in writing and reading began before the first grade, when his teacher assigned copying letters and numbers and he was not able to do this. His difficulties increased at the beginning of the first grade, especially in word decoding and he used a drawing or copying strategy in the dictation assignments- he wrote words in first grade as a whole pattern. Also, he had difficulties in reading and in grapheme-phoneme correspondence.

RL has been studying in the same school since he was 3 years old. After the diagnosis, he was integrated through a remediation project and was instructed by a remediation teacher. RL has not been treated by learning disabilities specialist, but just got private lessons from a tutor who supported him educationally and assisted him in his homework. Nowadays, RL is getting assistance only during the exams period, and is not getting any remediation at school. His mother reported that RL refuses to do homework and he gets angry while doing homework.

Educationally, RL prefers to learn chemistry, physics, history, electronics, sport, Arabic and mathematics. On the other hand, he does not like English and Hebrew.

Socially, RL is an admired teenager among his peers and other pupils in his school as well as by the teachers RL is a friendly, self-confident teenager and has a sense of humor. RL likes playing electronic games, spending time with friends and sleeping. Every week, RL goes for picnics with his family and rides horses. He uses the electronic media and internet very well, and although he knows how to use the Microsoft WORD software, he rarely uses it.

Stimuli: In the present study, six types of tests were used to examine the performance of RL in different categories.

First, in order to examine RL's general performance the Wechsler (WISC) Similarities test was administered. Similarities are a measure of concept formation. In this test, the subject is asked to describe how two given things are alike, e.g.: how are banana and apple alike?

Second, three reading tests were administered in order to examine the RL's reading abilities in standard Arabic:

a. Reading of single words: The test included 15 standard Arabic words that are frequent and common for standard and spoken Arabic. For example: مدرسة, بيت, خانت (see Appendix 1).

b. Reading of non-words: The test included 15 non-words that were constructed from patterns of frequent words in Arabic. For example: جاهر, دون (see Appendix 2).

c. Reading of standard Arabic text: The test was a story for children aged 10 years old that consisted of 107 words. The text was written with minimal punctuation in order to dismiss homographs (see Appendix 3).

Third, a spelling test was administered in order to examine RL's performance in writing and in the phoneme-grapheme transition of common word patterns in Arabic. The words were chosen from the text that he read in the previous test (see Appendix 4).

Fourth, RL was requested to read a spoken Arabic text that was written in Latin letters. The text was part of scientific article from an Arabic Scientific website. The text deals with smoking which is a topic of interest for teenagers. The text was translated to spoken Arabic. Then, the test was written in Latin letters according to the common system of writing small messages and emails among the Arabic population (see Appendix 5).

Fifth, a spelling test was administered. RL was requested to write a Spoken Arabic text in Latin letters using paper and pencil. The text is a part of an article about Arabian horses from a specific website that deals with horses which is one of RL's hobbies. The text was written in standard Arabic, then, it was translated to spoken Arabic (see Appendix 5).

Sixth, another spelling test was administered. RL was requested to write a Spoken Arabic text in Latin letters on his personal electronic device. The text was the continuation of the previous text about horses (see Appendix 6).

\section{PROCEDURE}

This study was conducted at R.L's house in a quiet room during the weekend. RL was instructed that the examinations were only for the purpose of this study. The study was conducted in one session which was divided into two parts with one break between parts. In the first part, the Arabic orthography reading and writing tasks were administered. In the second part, the reading and writing tasks that were written with the improvised Latin-Arabic writing system were administered.

\section{Results}

The RL's performance on the various qualitative and quantitative measures of cognitive and linguistic tests is reported separately.

Ability measure: RL's raw score in the Similarities Test from WISC was 14. This performance referred to a 
standard score $=10$ that is within the norms for his age.

Reading tests: In the single words reading test, RL read 10 words correctly out of 15 words. In other words, his accuracy percentage was $66.7 \%$. In the non-words reading test, RL read 10 words correctly out of 15 words. In other words, his accuracy percentage was $66.7 \%$ (see errors types, Table 1 ).

In reading a text, RL made 36 errors out of 107 words. In other words, his accuracy percentage was $66.7 \%$. His speed was 15.7 words in a minute (see Figure 2 and Figure 3).

His reading in this text was very slow, he read each syllable separately and he was having difficulty during his reading.

TABLE. I

ERROR TYPES (ACCORDING TO ABU-RABIA \& TAHA (2004).

\begin{tabular}{|c|c|}
\hline The test & Types of Errors \\
\hline Single words reading & 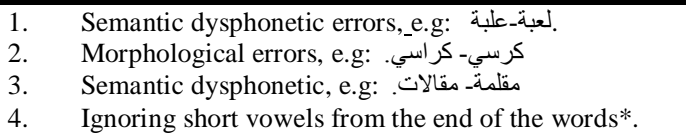 \\
\hline Non-words reading test & $\begin{array}{l}\text { 1. Vowel confusion errors: he read the long vowels as } \\
\text { short vowels, e.g: مار - مر } * \text { a } \\
\text { 2. Letter confusion errors: he read the "L" as "A" when } \\
\text { "L" is connected to another letter.* }\end{array}$ \\
\hline Text reading (Standard Arabic) & 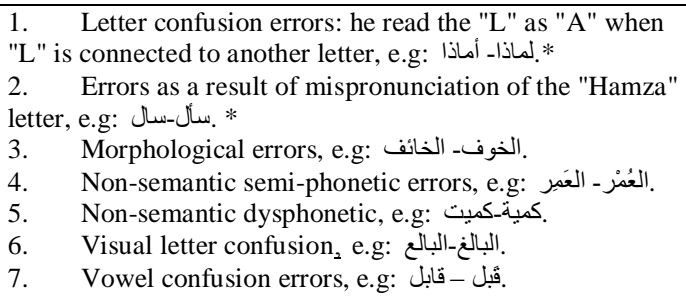 \\
\hline Words spelling test & Phonetic errors, e.g: طفلة- طفلا \\
\hline
\end{tabular}

In reading a spoken text that was written with Latin letters, RL read each syllable separately, but he controlled his reading process. RL read with $88.9 \%$ accuracy. His speed was 13.3 words a minute.

A paired t-test was used to estimate their relationship to one another by examining whether the mean performance in Latin letters was equal to the mean performance in Arabic. In Latin letters, RL exhibited almost fluent reading, whereas in Arabic letters his reading was characterized by stops pauses and visually-based errors. A paired-samples t-test disclosed a significant difference between his performance in the two orthographies $(\mathrm{t}(2)=11, \mathrm{p}<0.05)$.

The paired $\mathrm{t}$ test of speed showed a non-significant difference between single letter and text reading $(\mathrm{t}=5.776, \mathrm{p}=$ n.s).

Spelling tests: In the words spelling test, RL achieved $20 \%$ accuracy. In the spelling test of a spoken language text where RL was asked to write in Latin letters manually, RL achieved $76 \%$ accuracy and his speed was 4.5 words in a single minute.

In the spelling test of a spoken language text where RL was asked to write in Latin letters using an electronic device, RL achieved $80 \%$ accuracy and his speed was 6.5 words in a minute.

Although the accuracy in the both manual and electronic spelling tests in the spoken language text did not differ significantly, $(\mathrm{t}=5.776, \mathrm{p}=\mathrm{n} . \mathrm{s})$, RL exhibited significant greater speed in reading words related to reading text $(\mathrm{t}=6.7$, $\mathrm{p}<0.01)$.

Standard vs. spoken Arabic: All data were analyzed by a paired t-test procedure in order to estimate the relationship between the two types of Arabic by examining whether the mean performance in spoken Arabic was equal to the mean performance in standard Arabic.

The paired t test of the two levels of the type of language variables yielded a non-significant difference between spoken Arabic and standard Arabic, $\{\mathrm{t}=2.189, \mathrm{p}=\mathrm{n} . \mathrm{s}\}$ indicating that the differences between the performance in spoken Arabic and standard Arabic were not significant.

Also, an additional paired t-test was conducted in order to estimate the relationship between the speed of reading and writing by examining whether the mean speed in reading is equal to the mean speed in the writing. The paired t-test yielded a non-significant difference between reading and writing, $\{t=4.477, p=n . s\}$ indicating that the differences between the speed in writing and reading were not significant. 


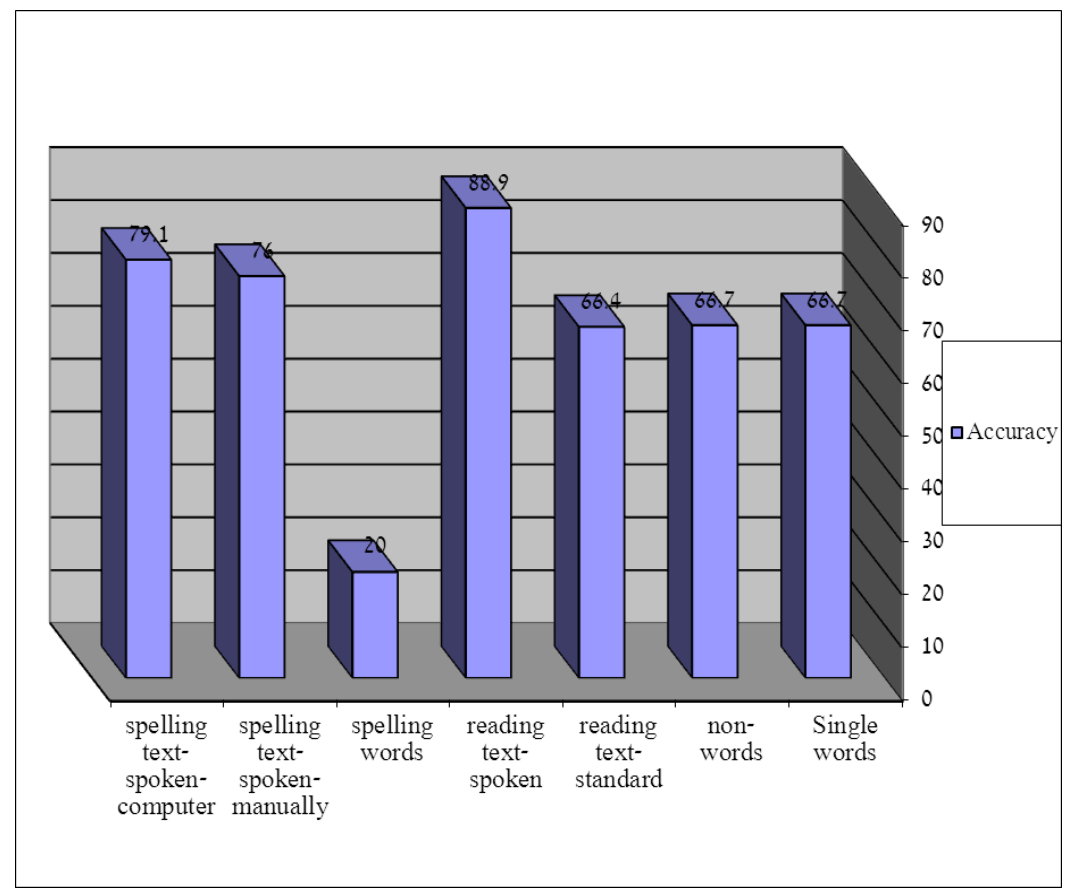

Figure 2. RL's accuracy percentages of RL in reading and spelling tests.

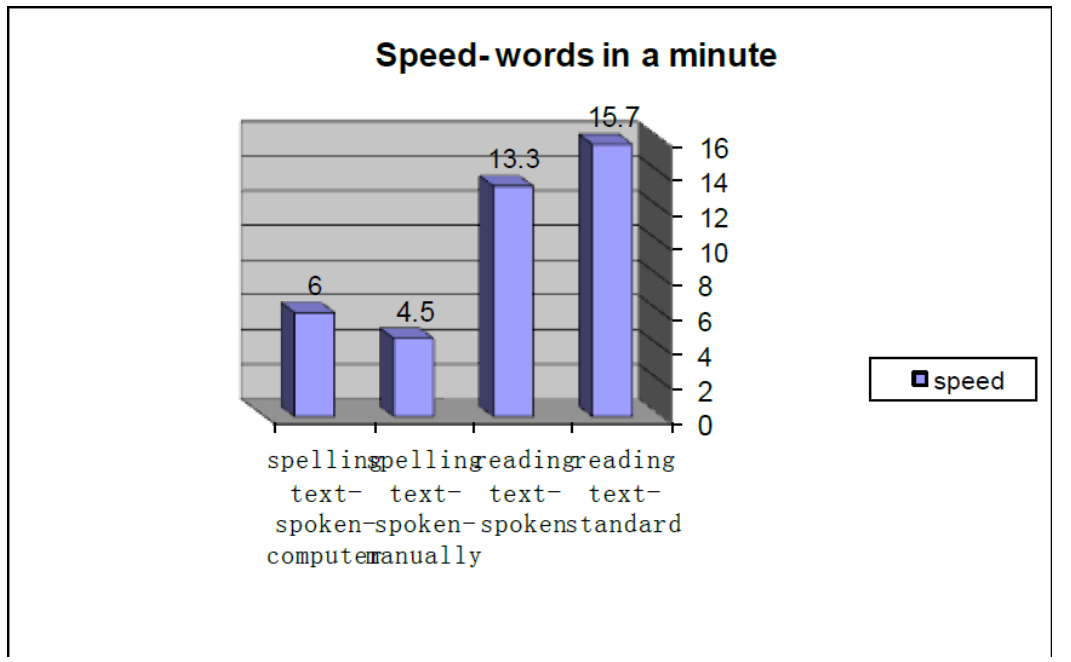

Figure 3. RL's speed (Words per minute) in the reading and spelling tests.

\section{Discussion}

The aim of this study was two folds: first, to examine the performance of a teenager (RL) who was diagnosed as learning disabled, in his reading and writing of Arabic words in Latin orthography compared to his reading and writing in Arabic orthography. Second, to examine RL's performance in writing Arabic text in Latin orthography manually versus writing on a computer.

RL's language skills as reflected in the reading measures suggest that he performs dissociatively when he deals with the two types of orthography (electronic vs. manual) but performs equally on the two forms of Arabic. RL's performance in writing a spoken Arabic text using electronic writing was better than manual writing. However, RL's performance on the tests shows that his performance in reading a text written in the improvised Arabic-Latin writing system was better than reading a text written in Arabic orthography. Furthermore, RL's performance L in writing a spoken Arabic text was better than writing a standard Arabic text. In addition, RL's good performance in writing and reading a text written in the improvised is indicative of RL's reading and writing difficulties in Arabic orthography. This finding is in line with the suggestion of Ibrahim, Eviatar, \& Aharon-Peretz (2002), that the characteristics of Arabic orthography, especially the visual complexity of Arabic letters, result in slowing the processing of Arabic orthography.

Abu Rabia \& Taha, (2004) argued that Arabic orthography includes many letters that are visually similar and phonologically different, which explains the errors caused by the confusion of grapheme representation of specific phonemes. Also, they claim that dyslexics suffer from the lack of Grapheme Phoneme Correspondence (GPC) 
manipulation ability, especially in orthography like Arabic where letters change shapes according to their position in the word. The findings of this study show that most of RL's errors in reading a text written in Arabic orthography were caused by the visual similarity of letters and letters that change their shapes according to their position in the word. At initial presentation, the connected items (which were matched for diacritical complexity) were actually read more quickly than the non-connected items. This finding is consistent with Abdelhadi et al. (2011) who also found a speed advantage for words with connecting letters among skilled adult readers of Arabic when performing a visual search task (see also Taha et al., 2013). The authors attributed this advantage to the fact that most printed words in Arabic consist of ligatured letters rather than non-ligatured letters. The present data, therefore, replicates this finding and extends it to young readers performing a standard word pronunciation task.

Another study that examined the effect of short vowelization on reading accuracy among dyslexics indicated that normal readers mastered the short vowels better than the dyslexics (Abu-Rabia, 2007). Dyslexics showed difficulty positing the correct short vowels on or under the correct letter to indicate correct pronunciation. Also, compared to the normal readers, they showed difficulty in syntactic awareness in posting diacritics on the ends of words to indicate grammatical function. In the current study, it was found that most of RL's errors were related to short vowelization.

In addition to the importance of short vowelization in Arabic to reading, the position of the letters in a word, and the changing of shapes according to their position in the word also effect reading fluency among dyslexics. RL explained his difficulties of reading Arabic orthography as related to the written form of Arabic letters. Since Arabic orthography is usually written with connected letters, RL has difficulty with fluency of word recognition. However, reading and writing in Latin letters is easier because the letters are separated in the words.

Furthermore, RL's good performance in reading and writing texts that are written in the improvised Arabic-Latin writing system can be explained by a full grapheme-phoneme correspondence, because each phoneme is represented by a specific letter or grapheme of the Latin letters.

The RL's good performance writing spoken language compared to writing standard Arabic may be caused by the fundamental characteristic of Arabic, diglossia. Studies that were conducted by Saiegh-Haddad, (2003; 2007) showed that Arabic- speaking children had more difficulty in phoneme isolation of standard Arabic words than phoneme isolation of spoken Arabic words. The researcher claimed that the phonological distance between the spoken language and the written language affects the acquisition of the basic reading processes such as phonological sensitivity and word decoding accuracy. In addition, diglossia interrupts the development of reading fluency indirectly, because it affects the speed of grapheme-phoneme conversion among young children.

The findings of this study support the assumption mentioned in the introduction and in the media of electronic devices that are used for educational and communicational purposes can affect reading skills. The use of the Facebook social network as well as other digital social programs that use short written electronic messages to communicate with others such as, "SKYPE", "MESSENGER" and others has grown tremendously. Using these electronic programs has caused the development of a new way of writing short messages among Arabic speakers. They have invented an Arabic-Latin writing system whereby they write colloquial Arabic words using the Latin letters. This improvised writing system is widespread throughout the social networks. Thus, it is reasonable to assume that RL's exposure to Latin (English) orthography in such social networks affected his performance in this study.

As electronic writing becomes more and more dominant, the idea that colloquial Arabic cannot be written, or cannot be written systematically, seems to disappear. This will mean that it will be much easier in Arabic-speaking societies to institute a program where a written version of the colloquial language is used in the very early grades to sensiblize the children to reading, such as those being used with other spoken languages (e.g Sinhala). Previously, this appeared to be problematic in Arabic because there was no established way to write the spoken language, but now because of the advent of electronic writing, such a system has begun to develop spontaneously. The use of this new type of writing, if it persists, may probably happen in the future if teachers are more convinced and familiar with this system, but it is probably that it will result in political fragmentation and debate. It is reasonable to suppose in this context that language developments will not only increase literacy, but also that it will represent an innovative use of a new media for writing which is clearly the wave of the future throughout the world.

\section{CONCLUSION}

This study shows that RL, an Arab teenager who suffers from reading difficulties or dyslexia, reacts positively and quickly to the use of electronic systems. These systems provide the support, assistance, facilitation and access to an educational environment (Williams, Jamali, \& Nicholas, 2006).

One limitation of this study is the shortage of comparable data regarding the reading and writing in a variety of spoken languages. In the absence of such data, we restricted ourselves to conclusions regarding the Arabic language. Obviously, further research is necessary before universal cross-linguistic conclusions can be drawn with a greater degree of confidence. Furthermore, the current findings encourage further examination of the impact of writing forms or the type of different orthographies on writing and reading among a large sample of dyslexics, and whether the Arabic orthography continues to be obstacle for learning in disabled teenagers. Furthermore, a future study should examine the impact of electronic usage on promoting learning for dyslexics and the effectiveness of electronic devices on reading and writing intervention among dyslexics. 
APPENDix A. Single Words

\begin{tabular}{|c|c|}
\hline عُعلبَة & مَذْرَسَة \\
\hline وَلدّ & مَفَلمَة \\
\hline وَرَْدَدَة & خاتم \\
\hline قلم & كلبّ \\
\hline و وادي & كرُسني \\
\hline دُكان & سبّارة \\
\hline كِتِاب & طاولة \\
\hline بَيْتِ & جَبَّل \\
\hline
\end{tabular}

APPENDIX B. NON WORDS

\begin{tabular}{|c|c|}
\hline دَوكَ & مَار \\
\hline مُوفَ & ظاهِن \\
\hline هُ"ك & قُقَن \\
\hline زارم & ساقِ \\
\hline راك & زاخ \\
\hline دَنَة & ثناتِب \\
\hline ليظ & مُدُاخ \\
\hline لَبَتَ & جاهِمِ \\
\hline
\end{tabular}

APPENDIX C. READING TEXT

تضحية طفل

يُحكى أن طفلة أصيبتثُ بمرض خطير و كانت حالتها حرجة جدا و كان أخو ها البالغ من العمر تسع سنو ات قد أصيب بنفس هذا

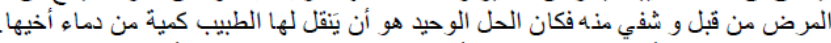

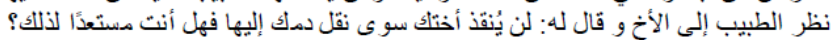

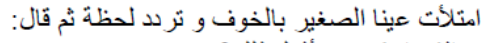

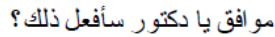

بعد ساعة من عملية النقل سأل الطفل بخوف:

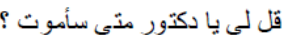

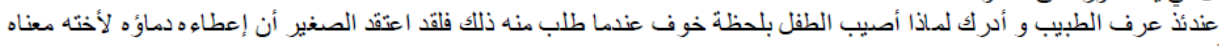
أنه بعطيها حياته نفسها

APPENDIX D. WORD SPELLING TASK

\begin{tabular}{|c|c|}
\hline مرض & طفلة \\
\hline تسع & جدًا \\
\hline خوف & دماء \\
\hline حياته & طلب \\
\hline قال & اعتقد \\
\hline
\end{tabular}

Appendix E. Spoken Arabic Text Spelling Test

$$
\begin{aligned}
& \text { الصفات الجمالية المطلوبة بالحصان العربي }
\end{aligned}
$$

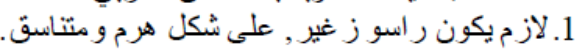

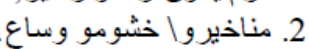

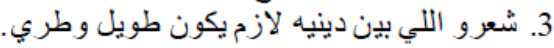

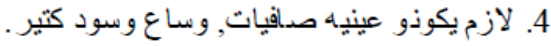

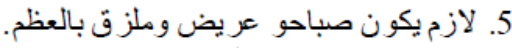

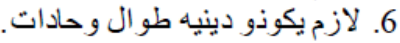

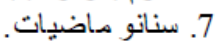

$$
\begin{aligned}
& \text { 8. } \\
& \text { 9. لازم يكوذو وآيديه طو ال وناصحئ. }
\end{aligned}
$$

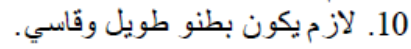

$$
\begin{aligned}
& \text { 11. لاز لازم يكون ديلو طويل وملان شعريل وماني }
\end{aligned}
$$

Appendix F. Spoken Arabic TeXt Spelling Test - Electronic 
1. Lazem ykon raso z3'eer w 3la shekel haram.

2. Mana7'ero \7'shomo wsa3.

3. Sha3ro elle ben denee lazem yekon taweel w tare.

4. Lazem ykono 3enee safyat, wsa3, w sood kteer.

5. Lazem yekon saba7o 3areed w mlaze2 bl 3adem.

6. Lazem ykono denee twal w 7adat.

7. Snano madyat.

8. Ra2ebto tawele.

9. Lazem ykono 2edee twal w nas7at.

10. Lazem yekon batno taweel w 2 ase

11. Lazem yekon deelo taweel w malan sha3ar.

STANDARD ARABIC TEXT

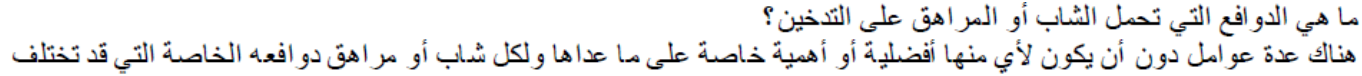

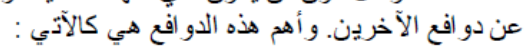

$$
\begin{aligned}
& \text { 1 } \\
& \text { 2. }
\end{aligned}
$$

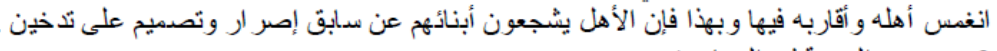

$$
\begin{aligned}
& \text { 3. }
\end{aligned}
$$

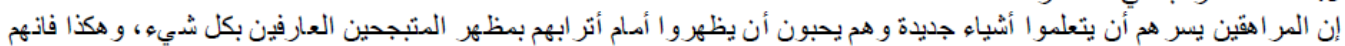

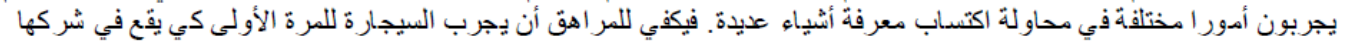

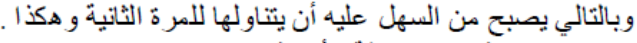

$$
\begin{aligned}
& \text { 4. } \\
& \text { الكثير من المر اهقين يخشون أن يختلفو الأعن غير هم لاعثقادهم أن هذا من شأنه أن يقلل من ترحيب رفقهم بهم } \\
& \text { 5 }
\end{aligned}
$$

COLLOQUIAL LANGUAGE TEXT

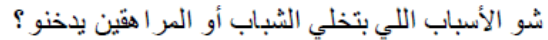

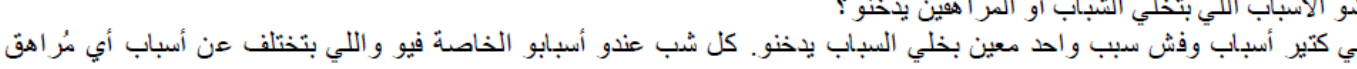

أهم الأسباب هيبي:

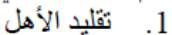

لما بكون الأبو أو الأم بدخنو, كثير هو اين على الولد يفكر بإنو الدخان مش خطر, لأذو إز أهلو أو أو قر اييو بدخذو معناتو هاد إنشي طبيعي

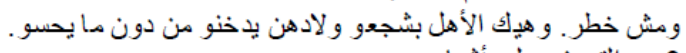

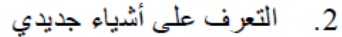

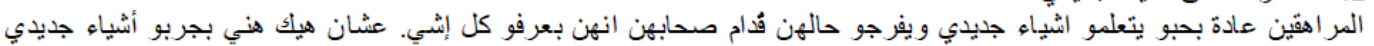
عشان ينعر فو على أشياء أكثر.

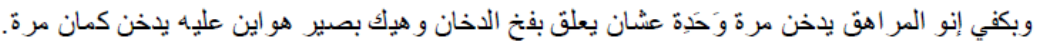

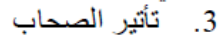

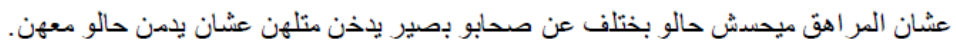

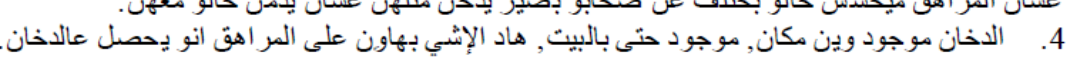

\section{REFERENCES}

[1] Abu-Ahamad, H., Ibrahim, R., \& Share. D.L. (In press). Cognitive Predictors of Early Reading Ability in Arabic: A Longitudinal Study from Kindergarten to Grade 2. In S. Elinor \& M. Joshi (Eds.), "Handbook of Arabic Literacy" - New York: Springer.

[2] Abu-Rabia, S. (1997). Reading in Arabic orthography: the effect of vowels and context on reading accuracy of poor and skilled native Arabic readers in reading paragraphs' sentences, and isolated words. Journal of Psycholinguistic Research, 26(4), 465-482.

[3] Abu-Rabia, S. Share, D. \& Mansoure, M. S. (2003). Word recognition and basic cognitive processes among reading- disabled and normal readers in Arabic. Readind and writing: An interdisciplinary journal, 16, 423-442.

[4] Abu-Rabia, S., \& Taha, H. (2004). Reading and spelling error analysis of native dyslexic readers. Reading and Writing: An Interdisciplinary Journal, 17, 651- 689.

[5] Abu-Rabia, S. (2007). The role of morphology and Short Vowelization in reading Arabic among normal and dyslexic readers in grades 3, 6, 9, and 12. Journal of Psycholinguist Research, 36, 89-106.

[6] APA. (1994). DSM-IV- Diagnostic and statistical manual of mental disorders. Fourth edition. Washington D.C.: American Psychiatric Association.

[7] Ayari, S. (1996). Diglossia and illiteracy in the Arab world, Language, Culture and Curriculum 9, $243-252$.

[8] Bishop, D. V. M., \& Snowling, M. J. (2004). Developmental dyslexia and specific language impairment: Same or different? Psychological Bulletin, 130, 858-886.

[9] Coltheart, M., Rastle, K., Perry, C., Langdon, R., \& Ziegler, J. (2001). DRC: A dual route cascaded model of visual word recognition and reading aloud. Psychological Review, 108, 204-256.

[10] Elbeheri, G. \& Everatt, J. (2007). Literacy ability and phonological processing skills amongst dyslexic and non-dyslexic speakers of Arabic. Reading and Writing, 20, 273-294. 
[11] Gallagher, A., Firth, U., \& Snowling, M.J. (2000). Precursors of Literacy Delay among Children at Genetic Risk of Dyslexia. Journal of Child Psychology and Psychiatry, 41(2), 203-213.

[12] Garra, E., (2007). From a dialect into a language: The cases of English and Arabic. Unpublished MA Thesis. Haifa: University of Haifa English Department.

[13] Ibrahim, R., Eviatar, Z., \& Aharon-Peretz, A. (2002). The characteristics of Arabic orthography slow its processing. Neuropsychology, 16, 322-326.

[14] Ibrahim, R., Eviatar. Z., \& Aharon Peretz, J. (2007). Metalinguistic awareness and reading performance: A cross language comparison. The Journal of Psycholinguistic Research.36, 297-317.

[15] Iraqi, J. Feitelson, F. \& Share, D (1992). Effects of listening to story reading on aspects of literacy acquisition in a diglossic situation. Reading Research Quarterly, 31, 31-53.

[16] Ferguson, Charles. (1959). Diglossia. Word, 15, 325-340.

[17] Katzir, T., \& Pare-Balagov, E. J. (2006). Applying Cognitive Neuroscience Research to Education: The Case of Literacy. Educational Psychologist, 41(6), 53-74.

[18] Khateb, A., Khateb, M., Taha, H., \& Ibrahim, R. (Submitted). The effect of the internal connectedness of written Arabic words on the process of the visual recognition: A developmental study.

[19] Lyon, R. G., Shaywitz, S. E., \& Shaywitz, B. A. (2003). A Definition of Dyslexia. Annals of Dyslexia, 53(1), 1-14.

[20] Myhill, J. (2009). Towards an Understanding of the Relationship between Diglossia and Literacy, a Survey Commissioned by the Language and Literacy Committee.

[21] OECD. (2010). PISA 2009 Results: What Students Know and Can Do - Student Performance in Reading. Mathematics and Science (Volume I).

[22] Palfreyman, D., \& Al-Khalil, M. (2003)."'A funky language for teenzz to use':Representing Gulf Arabic in instant messaging". Journal of Computer-Mediated Communication, 9 (1).

[23] Saiegh-Haddad, E. (2003). Linguistic distance and initial reading acquisition: The case of Arabic diglossia. Applied Psycholinguistics, 24(3), 431-451.

[24] Saiegh-Haddad, E. (2005). Correlates of reading fluency in Arabic: Diglossic and orthographic factors. Reading and Writing, 18, 559-582.

[25] Saiegh-Haddad, E. (2007). Linguistic constraints children's ability to isolate phonemes in Arabic. Applied Psycholinguistics, 28, 607-625. "doi: 10.1017/S0142716407070336"

[26] Snowling, M.J. (2000). Dyslexia 2nd edition. Oxford: Blackwell.

[27] Stanovich, K.E., Siegel, L.S. and Gottardo, A. (1997). Progress in the search for dyslexia subtypes. In C. Hulme and M. Snowling (Eds), Dyslexia: Biology. London Cognition and Intervention: Whurr.

[28] Stein, J. (2001). The magnocellular theory of developmental dyslexia. Dyslexia: An International Journal of Research and Practice, 7, 12-36.

[29] Taha, H., Ibrahim, R., \& Khateb, A. (2012). How Does Arabic Orthographic Connectivity Modulate Brain Activity During Visual Word Recognition: An ERP Study. Brain topography. doi:10.1007/s10548-012-0241-2

[30] Taouk, M. \& Coltheart, M. (2004) Learning to read in Arabic. Reading and Writing, 17, $27-57$.

[31] Vellutino, F. R., Fletcher, J. M., Snowling, M. J., \& Scanlon, D. M. (2004). Specific Reading Disability (Dyslexia): What We Have Learned in The Past Four Decades? Journal of Child Psychology and Psychiatry, 45(1), 2-40.

[32] Warschauer, M., G. El Said, and A. Zohry. (2002). "Language choice online: Globalization and identity in Egypt". Journal of Computer-Mediated Communication 7 (4).

[33] Wheeler, D.L. (2003). "The Internet and youth subculture in Kuwait." Journal of Computer-Mediated Communication 8 (2).

[34] Williams, P., Jamali, H. R., \& Nicholas, D. (2006). Using ICT with people with special education needs: what the literature tells us. Aslib Proceedings, 58(4), 330-345.

[35] Zabell, C., \& Everatt, J. (2002). Surface and Phonological Subtypes of Adult Developmental Dyslexia. Dyslexia, 8, 160-177.

Raphiq Ibrahim is a senior researcher at the Edmond J. Safra Brain Research Center for the Study of Learning Disabilities at the University of Haifa, where he is an Associate Professor of Neuropsychology. His main research interests are in psycholinguistics and neuropsychology, focusing on the cognitive and neurocognitive processing of oral and written language in both monolinguals and bilinguals.

Haitham Y. Taha is a researcher in the field of learning disabilities. His main interest is in investigating the basic cognitive and neurocognitive process in reading among typical and disabled native Arab readers. His main research work is being done at the Edmond J. Safra Brain Research Center for the Study of Learning Disabilities at University of Haifa and in the Reading and Cognitive Lab at Sakhnin College in Israel. Currently, Dr. Taha is the chair of the Special Education Department at Sakhnin College.

Ayat Abu Dabous is an MA student in the Department of Learning Disabilities at the University of Haifa. She is interested in reading and reading disabilities among native Arab readers.

Asaid Khateb is a senior researcher at the Edmond J. Safra Brain Research Center for the Study of Learning Disabilities at University of Haifa, where he is an Associate Professor of Neuropsychology. He is investigating brain regions involved in language selection processes in bilinguals, brain basis of diglossia in the Arabic language among Arabic-Hebrew bilinguals and clinical case studies in neuropsychology. Professor Asaid Khateb co-founded with Professor Alan Pegna the Laboratory of Experimental 
Neuropsychology, as part of the Clinical Neuropsychology Unit at Geneva University Hospitals (Switzerland). Currently, he heads the "Neurocognitive Laboratory for the Study of Bilingualism" and the Unit for the Study of Arabic Language" Edmond J. Safra Brain Research Center for the Study of Learning Disabilities at University of Haifa. 